\title{
Intrauterine Misoprostol versus intravenous Oxytocin infusion during cesarean delivery to reduce intraoperative and postoperative blood loss: a randomised clinical trial
}

\author{
Ahmed A. Abdelaleem ${ }^{1}$, Nasser A. Abdelaleem², Ahmed M. Abbas ${ }^{1 *}$
}

\begin{abstract}
${ }^{1}$ Department of Obstetrics and Gynecology, Faculty of Medicine, Assiut University, Assiut, Egypt
${ }^{2}$ Department of Obstetrics and Gynecology, El-Iman General Hospital, Assiut, Egypt
\end{abstract}

Received: 01 February 2019

Accepted: 06 March 2019

\section{*Correspondence:}

Dr. Ahmed M. Abbas,

E-mail: bmr90@hotmail.com

Copyright: (c) the author(s), publisher and licensee Medip Academy. This is an open-access article distributed under the terms of the Creative Commons Attribution Non-Commercial License, which permits unrestricted non-commercial use, distribution, and reproduction in any medium, provided the original work is properly cited.

\begin{abstract}
Background: The objective of the present study was to compare the efficacy of intrauterine misoprostol with intravenous oxytocin infusion in reducing blood loss during and after cesarean section (CS).

Methods: An open, randomized, clinical trial, registered (ClinicalTrials.gov ID: NCT03148574) conducted between July 1, 2017 and April 1, 2018. The study included 240 pregnant females that were recruited at term (37-40 weeks) gestation scheduled for either elective or emergency CS. Eligible participants were randomly allocated into two equal groups: Group A: patients who receive intravenous infusion of $10 \mathrm{I} . \mathrm{U}$ diluted to $500 \mathrm{ml}$ of normal saline for 30 minute after delivery. Group B: patients received $400 \mu \mathrm{g}$ misoprostol intrauterine just after cord clamping and delivery of the placenta. Primary outcome measure was assessment of amount of intraoperative and postoperative blood loss.

Results: The intraoperative and $2 \mathrm{~h}$ postoperative blood loss in the misoprostol group was higher than oxytocin group $(\mathrm{p}<0.001)$. Hemoglobin level decreased significantly among both groups, manifested by the highly significant $\mathrm{p}$ value in comparison of pre and postoperative $\mathrm{Hb}$ level in the two groups $(\mathrm{p}<0.001)$. However, the blood loss in the misoprostol group was higher than oxytocin group $(\mathrm{p}=0.004)$. There was a statistical significant differences between both groups as regards the need for additional uterotonic drug $(66 \%$ in misoprostol group vs $5 \%$ in oxytocin group, $\mathrm{P}<0.001)$. Shivering and pyrexia were more in common in the misoprostol group while vomiting, headache and giddiness were significantly higher among oxytocin group.

Conclusions: Administration of misoprostol $400 \mathrm{mcg}$ through intrauterine route appears to be less effective than intravenous oxytocin infusion in reducing blood loss during and after CS.
\end{abstract}

Keywords: Cesarean section, Misoprostol, Oxytocin, Postpartum hemorrhage

\section{INTRODUCTION}

Postpartum hemorrhage (PPH) from uterine atony is the leading cause of maternal mortality that can occurs in both vaginal and cesarean deliveries. ${ }^{1}$ Nowadays, cesarean section (CS) is increasing in both developed and developing countries. ${ }^{2,3}$ Prevention of $\mathrm{PPH}$ in this group is important to safe maternal life. Oxytocin has been routinely used to prevent uterine atony and excessive uterine bleeding during CS. However, despite its effectiveness, $10-40 \%$ of cases need additional uterotonics to ensure good uterine contraction. ${ }^{4-6}$

Misoprostol is a prostaglandin E1 analogue with good uterotonic properties and few adverse effects at therapeutic dose. It can be used oral, sublingual, buccal, 
rectal and intrauterine. ${ }^{7-10}$ Beside that, it can be used for termination of pregnancy in cases of missed or incomplete miscarriage. ${ }^{11-13}$ Also, in cases with retained placenta it may have a role in management of associated bleeding which mostly result from atony. ${ }^{14,15}$ In the field of gynecology, misoprostol could be used for induction of cervical ripening before office gynecological procedures. ${ }^{16-18}$ This could decrease the associated pain induced by transcervical passage of instruments.

The aim of the current study is to compare the efficacy of intrauterine misoprostol with intravenous oxytocin infusion in reducing blood loss during and after CS.

\section{METHODS}

The present study was an open, randomized, clinical trial, registered (ClinicalTrials.gov ID: NCT03148574) which was conducted at Assiut University, Women Health Hospital, in the period of time between July 1, 2017 and April 1, 2018.

The study included 240 pregnant females that were recruited at term (37-40 weeks) gestation scheduled for either elective or emergency CS. Following the approval of Assiut Medical School Ethical Board and obtaining informed permission from each patient, and following a written informed consent, all patients were subjected to clinical assessment including full history taking and physical examination. Sonographic evaluation were offered to all study subjects with special emphasis on placental localization and estimation of the expected date of the delivery.

\section{Inclusion criteria}

- Uncomplicated pregnancy, gestational age of 37-40 completed weeks

- Had no hypersensitivity or contraindications to prostaglandins.

- Had no history of coagulopathy

- Accepting to participate in the study.

\section{Exclusion criteria}

- Women with anemia (Haemoglobin $<8 \mathrm{~g}$ ).

- Placental abnormalities (e.g. placenta previa, placenta abruption)

- History of complications at previous pregnancy especially post partum hemorrhage

- Maternal hypertension, current or previous history of heart disease, liver, renal disorders.

Eligible participants were randomly allocated into two equal groups:

\section{Group A: 120 patients}

Patients who receive intravenous infusion of $10 \mathrm{IU}$ oxytocin (Syntocinon 10IU/1ml ampoule-Sandoz pharmaceutical) diluted to $500 \mathrm{ml}$ of normal saline for 30 minute after delivery of the neonate.

\section{Group B: 120 patients}

Patients who received $400 \mu \mathrm{g}$ misoprostol intrauterine just after cord clamping and delivery of the placenta (2 cytotec tablets each $200 \mu$ g-Pfizer).

If the uterus remained atonic despite the trial intervention, the obstetrician/anesthetist could use an additional uterotonic agent as oxytocin 5IU IV bolus and this was recorded.

CS was done under spinal anesthesia by senior obstetricians. Estimation of blood loss was started after skin incision. A dedicated nurse was responsible for collection of blood and amniotic fluid in two separate suction sets and weighting surgical towels before and after the operation in all cases of the study. To avoid individual bias, we use the same scales. Postpartum blood loss during the first $2 \mathrm{~h}$ after the operation was assessed by weighting soaked napkins.

Measurement of the operative blood loss was standardized including number of the disposable pads used, weight of soaked pads (in which all the soaked pads were weighed on a weighing scale which was then subtracted from the initial weight of dry pads). A 100 gram increase in weight was considered to be equivalent to $100 \mathrm{ml}$ of blood loss, measuring the volume of blood in the suction apparatus, and more objective measures of blood loss were calculated using pre- and post-operative hemoglobin and hematocrit values.

Baseline demographic data including age, weight, height, gravidity, gestational age and indication for the current cesarean section were recorded. The need for additional oxytocic therapy, infusion volume given intraoperatively, need for blood transfusion and side effects of the study drug were also recorded, also $\mathrm{Hb}$ and hematocrit values were noted before delivery and 24 hours post partum. The uterine tone and size were assessed postoperatively, by using a hand resting on the fundus and palpating the anterior wall of the uterus.

The side effects of each drug as nausea, vomiting, shivering, pyrexia and headache or others were noted. The main outcome measures for each case in each group were registered in the patient input form

\section{Study outcomes}

Primary outcome measure was assessment of amount of intraoperative and postoperative blood loss.

Secondary outcomes measures were the differences between pre and postoperative ( $24 \mathrm{~h}$ after CS) hemoglobin concentration and hematocrit values, the need for additional uterotonic drugs and incidence of side effects. 


\section{Statistical analysis}

The data were collected and entered onto Microsoft access database to be analyzed using the Statistical Package for Social Science (SPSS Inc., Chicago, version 21). Comparisons between two groups were done using Student's t-test to compare the mean values between groups in scale variables. However, Chi 2 test were used to compare the dichotomous and ordinal variables in the groups. For analysis, the level of significance (P-value) can be explained as (no significance $P>0.05$, significance $\mathrm{P}<0.05$, high significance $\mathrm{P}<0.001)$. For non-parametric continuous or categorical data, suitable tests as Fisher exact and Man-Whitney tests were used.

\section{RESULTS}

The baseline characteristics of the study participants are not statistically different (Table 1). Previous CS was the most common indication for CS $(36.67 \%)$, followed by fetal distress $(15.83 \%)$, then breech presentation $(11.67 \%)$.
Other factors were indications for CS in only minorities of cases. No significant difference between both groups.

Table 2 shows that the intraoperative and $2 \mathrm{~h}$ postoperative blood loss in the misoprostol group was higher than oxytocin group, with high significant difference between both groups $(p<0.001)$. The hemoglobin level decreased significantly among both groups, manifested by the highly significant $p$ value in comparison of pre and postoperative $\mathrm{Hb}$ level in the two groups $(\mathrm{p}<0.001)$. However, the blood loss in the misoprostol group was higher than oxytocin group, manifested by the significant postoperative difference between the two groups $(\mathrm{p}=0.004)$.

There was a statistical significant difference between both groups as regards the need for additional uterotonic drug $(66 \%$ in misoprostol group vs. $5 \%$ in oxytocin group, $\mathrm{P}<0.001)$. On the other hand, blood transfusion and IV fluid administration showed non-significant difference between the two groups.

Table 1: The baseline characteristics of the study participants.

\begin{tabular}{|c|c|c|c|}
\hline Variables & Oxytocin $(n=120)$ & Misoprostol (n=120) & P value \\
\hline Age (years) & $25.07(4.3)$ & $25.47(4.7)$ & $0.496(\mathrm{NS})$ \\
\hline \multicolumn{3}{|l|}{ Gravidity } & \multirow{3}{*}{$0.888(\mathrm{NS})$} \\
\hline Primigravida & $35(29.2 \%)$ & $36(30 \%)$ & \\
\hline Multigravida & $85(70.8 \%)$ & $84(70 \%)$ & \\
\hline Gravidity (mean) & $2.27 \pm 1.18$ & $2.5 \pm 1.4$ & $0.164(\mathrm{NS})$ \\
\hline Parity (mean) & $1.05 \pm 0.93$ & $1.23 \pm 1.17$ & $0.180(\mathrm{NS})$ \\
\hline \multicolumn{3}{|l|}{ Abortion } & \multirow{3}{*}{$0.117(\mathrm{NS})$} \\
\hline History of abortion & $21(17.5 \%)$ & $31(26.5 \%)$ & \\
\hline No history of abortion & $99(82.5 \%)$ & $89(73.5 \%)$ & \\
\hline Pt weight (kg) & $80.47(4.26)$ & $79.99(4.28)$ & $0.382(\mathrm{NS})$ \\
\hline Pt height $(\mathrm{cm})$ & $167.6(2.5)$ & $168.3(9.8)$ & $0.486(\mathrm{NS})$ \\
\hline Gestational age (in weeks) & $38.22(1.07)$ & $38.42(0.01)$ & $0.134(\mathrm{NS})$ \\
\hline
\end{tabular}

Data are presented as Mean (SD), or $\mathrm{n}(\%)$ as appropriate. $\mathrm{NS}=$ not significant.

Table 2: Comparison between both groups as regards blood loss.

\begin{tabular}{|l|l|l|l|l|}
\hline Groups & Oxytocin & Misoprostol & t-test & P value \\
\hline Intraoperative blood loss $(\mathrm{ml})$ & $387.69 \pm 47.11$ & $470.9 \pm 68.43$ & 10.972 & $<0.001(\mathrm{HS})$ \\
\hline 2 hours postoperative blood loss $(\mathrm{ml})$ & $55.8 \pm 31.7$ & $95 \pm 35.6$ & 9.008 & $<0.001(\mathrm{HS})$ \\
\hline Overall blood loss $(\mathrm{ml})$ & $442.78 \pm 56.43$ & $565.7 \pm 63.5$ & 15.851 & $<0.001(\mathrm{HS})$ \\
\hline
\end{tabular}

Data are presented as Mean \pm SD. HS=highly significant.

Table 3: Comparison between both groups as regards side effects of drugs.

\begin{tabular}{|c|c|c|c|c|}
\hline Side effect & Oxytocin & Misoprostol & Chi square & P value \\
\hline Pyrexia & $1(0.85 \%)$ & $9(7.5 \%)$ & 0.338 & $0.009(\mathrm{~S})$ \\
\hline Shivering & $2(1.7 \%)$ & $67(55.8 \%)$ & 85.939 & $<0.0001(\mathrm{HS})$ \\
\hline Vomiting & $27(22.5 \%)$ & $2(1.7 \%)$ & 24.511 & $<0.0001(\mathrm{HS})$ \\
\hline Headache & $18(15 \%)$ & $3(2.5 \%)$ & 11.742 & $0.0006(\mathrm{HS})$ \\
\hline Giddiness & $11(9.2 \%)$ & $2(1.7 \%)$ & 11.528 & $0.010(\mathrm{~S})$ \\
\hline
\end{tabular}

Data are presented as $\mathrm{n}(\%)$ as appropriate. $\mathrm{S}=$ significant, $\mathrm{HS}=$ high significant. 
Table 3 shows the side effects in both groups. Shivering and pyrexia were more in common in the misoprostol group while vomiting, headache and giddiness were significantly higher among oxytocin group. No significant differences as regards uterine atony in the postpartum period of follow up $(\mathrm{P}=0.392)$.

\section{DISCUSSION}

In the present study, intrauterine misoprostol can reduce the intra-operative blood loss during CS under regional anesthesia and within the first 2 hours post-operative but less effective than intravenous oxytocin infusion during CS.

The mean intraoperative blood loss was significantly higher in the misoprostol group compared with the oxytocin group as measured by visual estimation by the operative staff in the operation theatre which depended mainly on the staff experience and on the number and weight of soaked pads and blood in the suction apparatus. In general, Visual estimation of blood loss by the operative staff is the prevalent method in spite of being claimed to be notorious and inaccurate by some investigators. ${ }^{19}$

Unlike Vimala et al, the estimated mean blood loss during CS was significantly lower among women receiving sublingual misoprostol 400mg $(819 \pm 236 \mathrm{ml})$ than among those receiving $20 \mathrm{IU}$ oxytocin $(974 \pm 285 \mathrm{ml}$, $\mathrm{p}=0.004)$ soon after delivery of the neonate..$^{20}$

Also in Owonikoko et al study, the two groups received either misoprostol 400mg sublingually or IV infusion of 20IU Oxytocin soon after delivery of the baby, there were no significant differences in the two groups in estimated blood loss during the surgery. ${ }^{21}$ The mean blood loss in the first $4 \mathrm{~h}$ after the surgery was significantly less in the misoprostol group than in the oxytocin group (58.2 \pm 20.7 vs $80.5 \pm 26.8 \mathrm{ml} ; \mathrm{P}=0.02)$.

The current study shows that hemoglobin level decreased significantly among both groups, manifested by the highly significant $\mathrm{p}$ value in comparison of pre and postoperative $\mathrm{Hb}$ level in the two groups $(\mathrm{p}<0.001)$. However, the blood loss in the misoprostol group was higher than oxytocin group, manifested by the significant postoperative difference between the two groups $(p=0.004)$. In Vimala et al, there was no difference between the two groups in terms of the pre-delivery and post-delivery hemoglobin values. The mean reduction of hemoglobin was $0.4 \mathrm{gm} / \mathrm{dl}$ in the misoprostol group and $0.6 \mathrm{gm} / \mathrm{dl}$ in oxytocin group. There were more women in the oxytocin group who needed additional oxytocics and had measured blood loss in excess of $1000 \mathrm{ml}$. However, this difference did not reach statistical significance. ${ }^{20}$

In present study, shivering and pyrexia were the pronounced side effects associated with misoprostol group when compared to oxytocin. The number of women who experienced shivering was higher in the misoprostol group (67 cases representing $55.8 \%$ of the misoprostol group vs 2 cases only representing $1.7 \%$ of the oxytocin group) ( $p<0.0001)$. Also, there was significant difference as regards pyrexia between the two groups $(\mathrm{p}=0.009)$. While vomiting, headache and giddiness were higher among oxytocin group $(\mathrm{p}<0.0001)$. Vomiting in oxytocin group was $(22.5 \%)$ while in misoprostol group $(1.7 \%) \quad(\mathrm{p}<0.0001)$. Headache in oxytocin group was $(15 \%)$ while in misoprostol group $(2.5 \%)(\mathrm{p}<0.0006)$. Giddiness in oxytocin group was $(9.2 \%)$ while in misoprostol group $(1.7 \%)$ ( $<<0.010)$. Shivering and pyrexia are common adverse effects of misoprostol use, occurring in $30 \%$ to $70 \%$ of cases. ${ }^{22}$

In Vimala et al study, the incidence of side effects such as pyrexia, shivering and metallic taste was significantly higher in misoprostol group compared to oxytocin group. $^{20}$ In Owonikoko et al study, the incidence of adverse effects like shivering/pyrexia was significantly higher in the misoprostol group than in the oxytocin group $(27 / 50$ vs $1 / 50, \mathrm{p}<0.001) .^{21}$

There are very few studies performed to assess the role of intrauterine administered misoprostol in prevention of excessive intra-operative blood loss during CS. In 2009, a study was done by Quiroga et al, in Spain to evaluate the efficacy of intrauterine misoprostol for prevention of obstetrical hemorrhage. in this study, the efficacy of intrauterine misoprostol was compared with a placebo, and both groups received 10IU oxytocin as IV infusion. Results showed that addition of intrauterine misoprostol diminished the necessity of additional uterotonics by $50 \%$, and decreased the loss of hemoglobin, and the fall in hematocrit value by $39.6 \%$ and $40.6 \%$ respectively. A potential weakness in Quiroga study was the application of 10IU of oxytocin intravenously after cord clamping in both groups, which could have had an influence on intraoperative blood loss. Quiroga concluded that intrauterine combination of misoprostol and oxytocin diminishes the post-cesarean blood loss with few adverse effects. $^{23}$

In a study conducted in China done by Xueqin in 2010 , intrauterine administered misoprostol was found to be effective in reducing blood loss intra-operatively and after 2 hours of the cesarean section with no adverse reactions. ${ }^{24}$ In this randomized trial 180 cases of hospitalpatients who underwent elective CS and who were at risk for PPH were randomly assigned into three groups, $800 \mathrm{mcg}$ Misoprostol intrauterine administration group, 20IU IV infusion oxytocin group and $600 \mathrm{mcg}$ Misoprostol oral administration group, with 60 cases in each group. Results showed that blood loss of the misoprostol group intra-operatively and 2 hours after the operation were significantly less than the oxytocin group $(\mathrm{P}=0.01)$, and there were no adverse reactions in two groups. There were no significant differences between the intrauterine misoprostol group and the oral misoprostol group as regards blood loss intra-operatively and 2 hours 
after operation $(\mathrm{P}>0.05)$, but the side effects in the oral group were significantly higher.

\section{CONCLUSION}

In conclusion, in comparison to other studies with different routes or different doses of misoprostol, present study showed that administration of small dose of misoprostol $400 \mathrm{mcg}$ through intrauterine route appears to be less effective than intravenous oxytocin infusion in reducing blood loss during and after CS.

\section{ACKNOWLEDGMENTS}

Authors acknowledge the great supervision of the chief mentor of the study Professor Mohamed Makarem who died shortly before finishing the work.

Funding: No funding sources Conflict of interest: None declared

Ethical approval: The study was approved by the Institutional Ethics Committee

\section{REFERENCES}

1. Abbas AM, Amin MT, Ali SS, Salem NZ. Maternal mortality: a tertiary care hospital experience in Upper Egypt. Int J Reprod Contracept Obstet Gynecol. 2017;5(5):1466-71.

2. Getahun D, Strickland D, Lawrence JM, Fassett MJ, Koebnick C, Jacobsen SJ. Racial and ethnic disparities in the trends in primary cesarean delivery based on indications. Am J Obstet Gynecol. 2009;201:e1-7.

3. Brennan DJ, Robson MS, Murphy M, O’Herlihy C. Comparative analysis of international cesarean delivery rates using 10-group classification identifies significant variation in spontaneous labor. Am J Obstet Gynecol. 2009;201:e1-8.

4. Abdelaleem AA, Abbas AM, Thabet AL, Badran E, El-Nashar IH. The effect of initiating intravenous oxytocin infusion before uterine incision on the blood loss during elective cesarean section: a randomized clinical trial. J Maternal-Fetal Neonatal Med. 2018:1-6.

5. Acharya G, Al-Sammarai MT, Patel N, Al-Habib A, Kiserud T. A randomized, controlled trial comparing effect of oral misoprostol and intravenous syntocinon on intra-operative blood loss during cesarean section. Acta Obstet Gynecol Scand. 2001;80:245-50.

6. Munn MB, Owen J, Vincent R, Wakefield M, Chestnut DH, Hauth JC. Comparison of two oxytocin regimens to prevent uterine atony at cesarean delivery: a randomized controlled trial. Obstet Gynecol. 2001;98:386-90.

7. Hamm J, Russell Z, Botha T, Carlan SJ, Richichi K. Buccal misoprostol to prevent hemorrhage at cesarean delivery: a randomized study. Am J Obstet Gynecol. 2005;192:1404-6.
8. Vimala N, Mittal S, Kumar S. Sublingual misoprostol versus oxytocin infusion to reduce blood loss at cesarean section. Int $\mathbf{J}$ Gynaecol Obstet. 2006;92:106-10.

9. Othman ER, Fayez MF, El Aal DE, Mohamed HS, Abbas AM, Ali MK. Sublingual misoprostol versus intravenous oxytocin in reducing bleeding during and after cesarean delivery: A randomized clinical trial. Taiwanese J Obstet Gynecol. 2016;55(6):791-5.

10. Shady NW, Sallam HF, Elsayed AH, Abdelkader AM, Ali SS, Alanwar A, et al. The effect of prophylactic oral tranexamic acid plus buccal misoprostol on blood loss after vaginal delivery: a randomized controlled trial. J Maternal-Fetal Neonatal Med. 2017:1-7.

11. Metwaly AB, Abbas AM, Al-Sakkaf M. The use of single dose of oral misoprostol $(600 \mu \mathrm{g})$ at home in management of first trimester miscarriages in ElMukala, Yemen. Int J Reprod Contracept Obstet Gynecol. 2017;5(5):1360-3.

12. Mitwaly AB, Abbas AM, Abdellah MS. Intra uterine extra-amniotic versus vaginal misoprostol for termination of second trimester miscarriage: A randomized controlled trial. Int J Reprod BioMed. 2016;14(10):643.

13. Mitwaly AB, Abbas AM. Intrauterine extra-amniotic misoprostol solution is effective for termination of second trimester missed abortion: a clinical pilot descriptive study. Thai J Obstet Gynaecol. 2017:610.

14. Maher MA, Sayyed TM, Elkhouly NI. Different routes and forms of uterotonics for treatment of retained placenta: a randomized clinical trial. J Maternal-Fetal Neonatal Med. 2017;30(18):2179-84.

15. Abbas AM. Different routes and forms of uterotonics for treatment of retained placenta: methodological issues. J Maternal-Fetal Neonatal Med. 2019;32(6):1048.

16. Abdellah MS, Abbas AM, Hegazy AM, El-Nashar IM. Vaginal misoprostol prior to intrauterine device insertion in women delivered only by elective cesarean section: a randomized double-blind clinical trial. Contracept. 2017;95(6):538-43.

17. Khalaf M, Amin AF, Sayed Z, El-Nashar IM, Abbas AM. A randomized double-blind controlled trial of two different doses of self-administered vaginal misoprostol for successful copper intrauterine device insertion. Middle East Fertil Soc J. 2017;22(4):2648.

18. Samy A, Abbas AM, Mahmoud M, Taher A, Awad $\mathrm{MH}$, Hussein $\mathrm{M}$, et al. Evaluating different pain lowering medications during intrauterine device insertion: a systematic review and network metaanalysis. Fertil Steril. 2019.

19. Duthie SJ, Ven D, Yung GL, Guang DZ, Chan SY. Discrepancy between laboratory determination and visual estimation of blood loss during normal delivery. Eur J Obstet Gynecol Reprod Biol. 1991;38(2):119-24. 
20. Vimala, N, Mittal S, Kumar S. Sublingual misoprostol versus oxytocin infusion to reduce blood loss at cesarean section. Int $\mathbf{J}$ Gynecol Obstet. 2006;92(2):106-10.

21. Owonikoko KM, Arowojolu AO, Okunlola MA. Effect of sublingual misoprostol versus intravenous oxytocin on reducing blood loss at cesarean section in Nigeria: a randomized controlled trial. J Obstet Gynaecol Res. 2011;37(7):715-21.

22. Kavle JA, Khalfan SS, Stoltzfus RJ, Witter F, Tielsch JM, Caulfield LE. Measurement of blood loss at childbirth and postpartum. Int $\mathbf{J}$ Gynecol Obstet. 2006;95(1):24-8.

23. Quiroga DR, Cantú MR, Tello GHE, Puente VM, Montemayor GR, Martínez MA. Intrauterine misoprostol for the prevention of bleeding cesarean. Ginecol Obstet Mex. 2009;77(10):469-74.

24. Xueqin ZH. Clinical observation of intrauterine placement Misoprostol in prevention of intraoperative and postoperative bleeding in cesarean section. China Medical Herald. 2010;25:039.

Cite this article as: Abdelaleem AA, Abdelaleem NA, Abbas AM. Intrauterine Misoprostol versus intravenous Oxytocin infusion during cesarean delivery to reduce intraoperative and postoperative blood loss: a randomised clinical trial. Int J Reprod Contracept Obstet Gynecol 2019;8:1662-7. 